\title{
AUDITORIA DE GESTÃO: UTILIZAÇÃO DE INDICADORES DE GESTÃO NO SETOR PÚBLICO
}

\author{
Ivan Ricardo Guevara Grateron \\ Mestre em Controladoria e Contabilidade - FEA/USP \\ Professor Agregado Decanato de Administracíon y Contaduria \\ De la Unversidad Centroccidental Lisandro Alvarado - DAC-UCLA
}

\section{INTRODUÇÃO}

A auditoria de gestão fornece uma análise profunda da empresa ou organismo auditor e, o mais importante, determina a aptidão da equipe, incluindo uma avaliação individual de cada executivo e sua adequação à estratégia da organização. Tal como diz Guzmán ${ }^{1}$,

"Os governos e as instituições enfrentam, na atualidade, grandes desafios. Garantir que está obtendo o maior benefício possível dos fundos públicos que gastam em suas organizações é um deles. Outro, é o de convencer ao público de sua transparência e a capacidade de render contas, assim como o uso de adequadas práticas administrativas. O governo não só deve ser econômico, eficiente e eficaz como deve ser capaz de demonstrá-lo".

No ambiente atual de agitação e turbulência tanto econômica quanto política, a auditoria de gestão deve converter-se em um instrumento ou ferramenta de avaliação da direção ou gestão em empresas ou organismos de qualquer natureza, setor ou tamanho.

Às vésperas do fim do segundo milênio, um grupo importante de empresas, as públicas e as privadas, tem travado uma incessante luta na busca de um melhor posicionamento competitivo nos mercados regionais e internacionais. Em um ambiente empresarial sujeito aos efeitos das mudanças das variáveis externas não controláveis pela empresa, as organizações estão condicionadas `a realização de revisões periódicas e sistemáticas dos procedimentos gerenciais utilizados, de modo que estes sejam adaptados às exigências do novo cenário econômico e social.

O termo gestão pode ser tratado como sinônimo de administrar, envolvendo, em alto grau, o processo de tomada de decisões, o que, no setor público corresponde a cuidar de bens alheios; não só no que diz respeito ao gestor, senão também da organização ou entidade auditada. A distribuição em forma razoável dos recursos de que se dispõe, visa obter os melhores resultados da gestão. Para quem dirige organizações do setor público, a tarefa principal é recolher impostos e, em troca, fornecer serviços e obras de caráter público sem desequilibrar a balança das receitas e despesas públicas.

Tudo isso parece ser totalmente oposto ao que têm feito os gestores públicos contemporâneos, deixando o erário público em situação, no mínimo, delicada. Quando isto ocorre nas empresas do setor privado, produz-se a falência ou quebra, o que não pode acontecer no Estado. Este, longe de cumprir a sua missão de gestor eficiente e eficaz dos recursos públicos, culmina por ter a imperiosa necessidade de reconhecer a sua evidente incapacidade como gestor, dando início ao chamado processo de privatização das empresas do Estado como uma clara manifestação de inaptidão generalizada para a atividade gerencial ao redor do mundo inteiro, com rara exceções.

\section{CONTEXTO DO PROBLEMA}

Em conseqüência do desenvolvimento do exercício de atividades profissionais relacionadas com auditoria em sua moderna conceituação e com enfoque centralizado na aplicação de indicadores e parâmetros como base para realizar a avaliação da gestão e do desempenho dos gestores, chama a atenção o estudo dos aspectos relacionados com a Auditoria de gestão no setor público como uma alternativa útil para auxiliar à direção na consecução das metas e objetivos propostos estrategicamente.

O setor público tem a obrigação de fornecer a satisfação de um amplo leque de necessidades sociais em contínua expansão exigindo, pois, uma gestão rigorosa dos recursos

${ }^{1}$ GUZMÁN, Miguel D. A auditoria compreensiva: um moderno concepto en la auditoria. México: 1991, p, 77. 
públicos limitados para poder cumprir suas obrigações sociais internas. A existência de recursos públicos limitados e escassos e a crescente exigência de maior qualidade de vida por parte da população, o considerável crescimento experimentado pelo setor público, assim como a grave crise social, econômica e financeira atualmente existente nos diferentes países do mundo, responsável por profundos desequilíbrios das estruturas sociais e econômicas e pela perda de confiança da sociedade nas instituições públicas e seus governantes, o grande volume e complexidade das operações que realiza a administração pública, todos esses fatos não deixam lugar para dúvidas quanto à imensurável necessidade de introduzir os conceitos, amplamente aplicados no setor privado, de economia, eficácia e eficiência nas atividades que realizam os gestores do setor público, de modo a estimular o aparato produtivo e fortalecer a relação oferta-procura de bens e serviços para a sociedade.

Um dos principais problemas que atinge as administrações públicas contemporâneas é a corrupção, e esta muitas vezes relacionada à falta de controle adequado sobre uma determinada gestão, implica um conjunto de atos que resultam no uso indevido dos recursos pertencentes ao Estado em benefício próprio ou de terceiros. Como alimento para o vício da corrupção, encontrase, nas administrações públicas contemporâneas, entre outras falhas, um crescimento da burocracia sem a devida adaptação dos sistemas de controle, acompanhado de desordem administrativa, falta de transparência nas transações governamentais realizadas, incoerência das leis ou ausência delas, clientelismo político, influência dos partidos políticos nos processos de controle, inexistência, obsolência e inadequação dos sistemas de controle, nos quais predomina o critério quantitativo sobre o qualitativo e legal da gestão.

Acrescente-se que os referidos sistemas de controle apresentam um alcance orientado especialmente aos aspectos de legalidade e regularidade contábil, em detrimento dos conceitos de eficiência, eficácia, economia e de resultados ou efeitos. Quanto à capacidade sancionadora, indispensável no contexto público, esses sistemas apresentam-na, porém de modo muito débil.

Deve ser considerado que o desenvolvimento de caráter tecnológico, social e, de modo geral, do Estado, ao redor do mundo, exige o desenho e aplicação de filosofias de gestão baseadas nos conceitos mais modernos de eficiência, eficácia e economia na gestão dos recursos públicos. Por isso, na atualidade, não se critica a introdução de técnicas de gestão avançadas no setor público; mas é importante destacar que os estudos e pesquisas neste sentido tem-se concentrado nos processos de produção industrial e comercial privados e em algumas atividades de prestação de serviços, deixando, à margem destes, análises no âmbito público.

Os objetivos do setor público são multíplices, ao contrário do que ocorre no setor privado em que, segundo Guerreiro ${ }^{2}$, o principal objetivo é a obtenção de benefícios ou lucro. Os governos, muito pelo contrário, fornecem serviços públicos e redistribuem as riquezas por diferentes motivos sociais e econômicos. Também se pode dizer que o benefício (ou lucro) que o governo persegue está expresso no bem comum da sociedade que representa; portanto, a atividade do setor público deve ser medida e avaliada mediante a utilização de parâmetros ou indicadores que decorram da eficiência e eficácia de modo que possam integrar os relatórios da entidade.

O sistema tradicional de contabilidade e de informação que auxilia o gestor não cumpre sua missão de garantir as melhores decisões ou, no mínimo, prestar-lhes suporte; por isso, é necessário considerar a possibilidade de um modelo que responda às necessidades de informação para contribuir com a melhoria de uma gestão que tem sido objeto permanente de crítica: a Gestão Pública. Com esta finalidade, devem-se definir os objetivos perseguidos pela contabilidade de gestão, para que se forneça informação oportuna e clara, permitindo a adoção das melhores decisões no momento mais oportuno. Assim, deverão ser consideradas algumas das principais ferramentas destinadas à otimização da gestão como, por exemplo, os orçamentos, os planos, sistemas de informações e de controle, etc.

Ë muito comum encontrar, na bibliografia técnica, marcadas divergências na delimitação do alcance ou âmbito de desenvolvimento de Auditoria de Gestão, em virtude, especialmente, do termo utilizado por alguns autores para definir o que outros designam com algum termo diferente tratando-se, no final, do mesmo conceito. Assim, pode-se encontrar a utilização do termo de Auditoria de Gestão como sinônimo de Auditoria de Economia, Eficiência e Eficácia, Auditoria

\footnotetext{
${ }^{2}$ GUERREIRO, Reinaldo. A meta da empresa: seu alcance sem mistérios. São Paulo: Atlas, 1996, p. 26.
} 
Governamental, Auditoria Compreensiva e até como uma extensão da função de Auditoria Interna Moderna. Uma outra divergência trata sobre a amplitude de cada uma e alguns autores chegam até a estabelecer hierarquias destes "tipos ou categorias" de auditorias.

Pode-se afirmar que o processo de mudanças, como uma conseqüência imediata da necessidade de adaptação às exigências do desenvolvimento tecnológico, é profundo e generalizado, atingindo, especialmente, o mundo dos negócios e seu cenário, onde aparece o contador público e o auditor. Sistemas de informações, Sistemas de Controle e Modelos de Gestão são apenas alguns aspectos que mais rapidamente devem adaptar-se às mudanças do cenário de forma que se possa garantir o atingimento eficaz e eficiente das metas e objetivos da organização, permitindo a sua sobrevivência no tempo ou a perenidade. A medição permanente da coerência entre as metas e objetivos e os resultados obtidos da administração dos recursos, no que diz respeito ao benefício social, através da utilização de parâmetros ou indicadores de gestão apropriados, é uma preocupação comum aos gestores públicos contemporâneos.

Assim, partindo-se das premissas de que $: 1^{\circ}$ ) a Gestão Pública precisa ser avaliada para conhecer e dar resposta ao cidadão, comum quanto ao grau de adequação e coerência existente entre as decisões dos gestores e a eficácia, eficiência e economia com que foram administrados os recursos públicos para serem atingidos os objetivos e metas da organização, estabelecidos nos planos e orçamentos, $2^{\circ}$ ) para realizar avaliação da gestão pública, é necessário considerar a possibilidade de um modelo de contabilidade desenhado para a gestão, que considere indicadores ou parâmetros de gestão adequados.

\section{AUDITORIA DA GESTÃO PÚBLICA: AUDITORIA DE ESTADO OU GOVERNAMENTAL}

As auditorias de gestão podem ser vistas com a revisão e avaliação da qualidade e oportunidade da informação. Podem ser realizadas por auditores gerenciais, externos ou internos e pelo órgão de fiscalização superior. A auditoria financeira não elimina a necessidade de uma rigorosa revisão, por parte da gerência, para determinar se a entidade pública auditada está atingindo, de forma efetiva, os objetivos para os quais foram aprovados os programas e recursos; se os procedimentos realizados para tal finalidade são eficientes; se os recursos alocados são suficientes e se estão sendo cumpridas as leis e regulamentos aplicáveis. Adicionalmente, a auditoria da gestão pública é necessária para avaliar a adequação dos programas e a existência de controle efetivo sobre as receitas e despesas.

Também pode ser utilizada a auditoria da gestão pública para avaliar se são aproveitadas todas as oportunidades para serem eficientes, eficazes e econômicas, com o objetivo de oferecer maior qualidade no serviço prestado e nos produtos fabricados, de modo a satisfazer as necessidades dos cidadãos, como donos dos recursos administrados e beneficiários dos produtos e serviços da administração pública.

Algumas perguntas têm favorecido o estudo e desenvolvimento da auditoria da gestão pública: 1) Podem os funcionários e administradores públicos basear a tomada de decisões nos relatórios e medições tradicionais? 2) São eficientes e efetivas as operações e processos da administração pública? 3) Existe um adequado controle das operações? 4) São bons os produtos e serviços públicos? Satisfazem as necessidades para as quais foram criados?

Os relatórios e medições referem-se, usualmente, aos relatórios contábeis e financeiros, tanto para o setor público quanto para o setor privado. A responsabilidade pública não se restringe aos aspectos de caráter financeiro e de orçamento, também inclui: a gerência dos processos, recursos, efeitos e resultados; a aplicação eficaz, econômica e eficiente; eliminação dos desperdícios de recursos; qualidade dos produtos e serviços públicos; a satisfação das necessidades, etc. Acrescenta-se que os gestores públicos têm a responsabilidade e compromisso de utilizar as melhores e mais modernas técnicas gerenciais.

Na prática, a informação financeira nas entidades do setor público, na maioria dos casos, tem sido elaborada com a simples finalidade de cumprir a lei e não fornece informação útil para satisfazer às necessidades gerenciais dos usuários.

No setor público, a Auditoria de Gestão nasce pela necessidade de enfrentar a crescente corrupção que envolve a burocracia dos governos contemporâneos nos países do mundo inteiro. A 
necessidade de prestar serviços e administrar os recursos do cidadão de maneira eficiente, econômica e eficaz, além da necessidade de fornecer instrumentos aos gestores públicos para demonstrar a transparência nos atos públicos, tem servido de base para o desenvolvimento da Auditoria de Gestão no campo do setor público na atualidade.

Algumas das premissas que suportam o contínuo desenvolvimento da Auditoria de Gestão no setor público é que o Estado, na alocação de recursos aos entes públicos que desenvolvem alguma atividade social ou pública, seja esta de produção de bens ou prestação de serviços, precisa contar com sistemas adequados que permitam exercer um controle sobre a captação/arrecadação e uso eficiente dos recursos. Além disso, o Estado precisa de bons sistemas de informação, que garantam, de forma oportuna e eficaz, a segurança dos registros e transações efetuadas e informações dos atos realizados.

$\mathrm{Na}$ adaptação da filosofia da Auditoria de Gestão ao setor público, pode-se qualificar esta como Auditoria de Estado ou Auditoria Governamental, se são considerados o alcance e objetivos que ela persegue. Neste sentido, deve-se destacar que no IX Congresso Internacional de Instituições Superiores de Auditoria (INCOSAI), realizado em outubro de 1977 em Lima - Peru, após uma série de discussões que tomaram alguns anos, aconteceu o fato que marcou o início da Auditoria de Gestão do Setor Público ou Auditoria Governamental. Foi emitida a "Declaração de Lima", com base na recomplicação de conceitos e definições apresentados desde o I Congresso de Havana, em 1953. Esta Declaração, juntou os princípios definidos com base na experiência, e esses constituíram-se nos padrões principais para o exercício da auditoria governamental , mostrando-se neles uma total relação entre a qualidade e a produtividade da auditoria de Estado.

A "Declaração de Tóquio" sobre aspectos da responsabilidade pública, adotados pela Associação de Instituições Superiores de Auditoria (ASOSAI) em 1985 e ratificadas no Congresso Internacional de Instituições Superiores de Auditoria (INCOSAI) de Sydney - Austrália, em 1986, destaca o enfoque da auditoria governamental e inclui os termos eficiência, eficácia e economia.

A partir daí, os critérios constantes na normativa emitida e desenvolvida pela International Organization of Suprem Audit Institutions (Organização Internacional de Instituições Superiores de Auditoria - INTOSAI) sobre Controle Interno, Contabilidade, Auditoria Governamental, Sistemas de Informação Computadorizada, Auditoria do Meio Ambiente, Auditoria da Dívida Pública, Auditoria para as Privatizações de Empresas Públicas, dentre outras, tem sido os critérios básicos para desenvolver a normativa técnica aplicável para cada país e, em conseqüência, para o desenvolvimento dos profissionais da auditoria no setor público.

Outros critérios que servem de base à INTOSAI são as N.I.C. (Normas Internacionais de Contabilidade) e as N.I.A (Normas Internacionais de Auditoria), emitidas e atualizadas periodicamente pelo Internacional Federation of Accountants - IFAC. Cada Instituto Superior de Auditoria tem desenvolvido as normas técnicas específicas a serem aplicadas, no exercício da auditoria governamental, nas entidades sujeitas ao controle do Estado. Assim, foram criadas normas neste sentido pelas I.S.A.S. em: Bolívia (1977), Venezuela (1977), Peru (1996), Equador (1994), Argentina (1993), Honduras e Panamá (1992).

\section{EXPERIÊNCIA INTERNACIONAL}

A Organização Internacional das Entidades Fiscalizadoras Superiores (INTOSAI) tem reconhecido dois tipos de auditorias na Auditoria da Gestão Pública. São elas as Auditorias de Regularidade e as Auditorias de Gestão ou Operativas. A primeira, Auditoria de Regularidade, compreende a Certificação das contas das entidades, revisões dos sistemas e das operações financeiras e a avaliação do grau de cumprimento das disposições legais aplicáveis. A segunda, a Auditoria de Gestão, compreende a avaliação da economia e eficiência com que a entidade auditada utiliza os variados recursos para realizar seus objetivos ou metas.

A Auditoria de Regularidade, forma tradicional de exercer a fiscalização pública, está orientada a realizar uma avaliação da correção e probidade das decisões administrativas na entidade auditada. Mesmo que se deva reconhecer a conveniência e necessidade de efetuar este tipo de auditoria, observa-se em alguns países a importância de se avaliarem, também, os 
resultados dos programas de governo fornecendo ações para melhorar a utilização dos recursos públicos. Surgiu assim a Auditoria de Regularidade no controle da gestão pública.

As entidades fiscalizadoras superiores, pioneiras no estudo e desenvolvimento da auditoria de gestão, são as entidades dos países de língua inglesa, em especial: Estados Unidos, Canadá, Reino Unido, Austrália e Nova Zelândia. Essas instituições começaram a estudar a Auditoria de Gestão em 1950, com destaque nos últimos 20 anos. Na década de 80, começa a ser aplicada nos países da América Latina.

A Auditoria de Gestão pode orientar a realizar uma avaliação da economia e eficiência das entidades auditadas ou a avaliar a eficácia e efetividade dos programas específicos de governo; ou seja, o objeto da Auditoria de Gestão pode ser uma instituição pública ou um programa em particular. Nos Estados Unidos, é utilizada preferencialmente para a avaliação de programas específicos de governo, enquanto no Canadá, Reino Unido, Austrália e Nova Zelândia, esse tipo de auditoria orienta-se para a auditoria parcial ou total da gestão da entidade.

Uma distinção importante no alcance das Auditorias de Gestão no setor público diz respeito ao fato de incluírem ou não juízos sobre as políticas governamentais. Nos Estados Unidos, o Escritório Geral de Contabilidade (G.A.O) determina se os objetivos de um programa, proposto ou em execução, são adequados e relevantes. No Canadá, Reino Unido, Austrália e Nova Zelândia as auditorias limitam-se a avaliar a economia e eficácia da gestão pública, sem questionar os méritos das políticas governamentais; ou seja, simplesmente informam aos legisladores se as políticas estão sendo bem implantadas, sem avaliar a adequação ou inadequação dessas políticas.

A Auditoria de Gestão tem permitindo também a discussão de alguns riscos e benefícios. As entidades fiscalizadoras superiores nos países de língua inglesa afirmam, de maneira uniforme, que a Auditoria de Gestão agrega muito mais valor ao serviço público que a Auditoria de Regularidade. Assim, cita Alberto Silva Aristiguieta ${ }^{3}$ as palavras do Controller Geral dos Estados Unidos que diz:

"Cada ano as auditoriais de gestão desenvolvidas pela Controladoria Geral dos Estados Unidos sob minha responsabilidade, tem conduzido a ações legislativas (poder legislativo) e executivas (poder executivo) originando-se delas importantes reduções orçamentárias, diminuição e eliminação de custos, diferimento de despesas e pagamentos, e arrecadação de receitas, o que tem nos levado a capitalizar grandes economias financeiras e outros benefícios avaliados em vários milhões de dólares."

Deve-se acrescentar que o controle de gestão, como controle interno, a Auditoria de Gestão (interna ou externa) como avaliação deste controle interno, passam a ter maior relevância como ferramenta fundamental de estímulo ao longo de uma administração caracterizada pela eficácia, eficiência, economia, probidade, legalidade, equidade e racionalidade, permitindo o desenvolvimento do país. Neste sentido, acredita-se que o exercício "cabal" das funções de controle, entendidas como elemento gerador de ações corretivas, em permanente ação pedagógica e orientadora da gestão pública, necessariamente se traduzirá em efeitos positivos (Diretos e Indiretos) como menor desperdício, economia na execução orçamentária, eficiência nos programas de investimento público, estímulo ao gestor honesto, diminuição na ocorrência de fatos delituosos e prejudiciais ao patrimônio público, incremento da eficiência administrativa pública e, em conseqüência, da gestão governamental.

\section{ALGUMAS PERGUNTAS E RESPOTAS SOBRE AUDITORIA DE GESTÃO PÚBLICA}

\section{O QUE É AUDITORIA DE GESTÃO?}

A Auditoria de Gestão é uma técnica ou atividade nova que presta consultoria aos mais altos extratos de uma organização, seja de caráter público ou privado. Procura mostrar os ponto os fracos e fortes da organização, estabelecendo as recomendações necessárias para melhorar o

\footnotetext{
${ }^{3}$ ARISTIGUIETA, Alberto Silva. La géstion pública.in: Seminário Nacional de Auditoria de Estado. Venezuela, 1997, p. 16.
} 
processo de tomada de decisões. Procura avaliar, baseada nos critérios ou parâmetros de eficiência, efetividade e economia, o processo de tomada de decisões e seu efeito no atingimento das metas e objetivos da organização. Em resumo, a Auditoria da Gestão pretende avaliar os resultados obtidos pela gestão no que tange a eficiência, eficácia e economia na consecução dos objetivos planejados.

\section{QUAIS SÃO AS RESPOSTAS QUE UMA AUDITORIA DE GESTÃO, NO SETOR PÚBLICO, DEVE FORNECER?}

As Auditorias de Gestão, de acordo com o Auditor Geral do Canadá - o que tem sido aceito pelas ISA'S (Instituições Superiores de Auditoria), também chamadas Entidades Fiscalizadoras Superiores devem dar resposta às seguintes perguntas e expectativas:

São manejados e administrados os programas com economia e eficiência?

- O governo possui os meios para medir a sua efetividade?

- Vale a pena executar os programas?

- O que se pode fazer para melhorar a gestão?

- Existem indicadores de medição da gestão pública? Aplicam-se corretamente?

- Existem sistemas de controle de gestão adequados?

\section{QUAL É A CONTRIBUIÇÃO DA AUDITORIA DE GESTÃO NO SETOR PÚBLICO?}

Como já foi referenciado, a Auditoria de Gestão faz-se mais complexa à medida que as empresas, qualquer que seja a sua natureza (pública ou privada), mudam a forma e metodologia de se avaliar a gestão. Tradicionalmente, a medição era realizada através de simples indicadores financeiros; da mesma forma, era realizada a auditoria, o que, nessa ótica, requeria um auditor com perfil contábil e financeiro. Atualmente, os aspectos não financeiros da gestão assumem maior relevância, assim como é mais importante o rumo e a visão da entidade no futuro, do que seu desempenho no passado e no presente.

A moderna Auditoria de Gestão, aplicada às empresas do Estado, assim como a qualquer entidade onde seja praticada, começa a agregar valor de forma imediata. Entre as diversas contribuições que aporta podem-se citar as seguintes: 1) Promove a medição da gestão; 2) Melhora os sistemas de medição; 3) Contribui à eficiência, eficácia e economia da gestão administrativa; 4) Contribui para obtenção de melhores rendimentos e receitas para a entidade, o que se traduz em maximizar o valor agregado para o Estado; 5) Promove a formação de auditores em áreas não tradicionais.

\section{OBJETIVOS DA CONTABILIDADE DE GESTÃO NO SETOR PÚBLICO}

A crescente preocupação, na maioria dos países do mundo, com a obtenção de eficiência, eficácia e economia na gestão dos recursos públicos faz que as informações geradas pelos relatórios financeiros da contabilidade tradicional não sejam suficientes nem mais apropriadas. A informação que fornece a Contabilidade de Gestão oferece uma visão global da entidade ou organismo; informação que é complementada com dados em detalhes sobre cada uma das partes da entidade e que está orientada a auxiliar os responsáveis da gestão na tomada de decisões. Os objetivos da contabilidade de gestão podem ser múltiplos, contudo existem alguns que devem ser destacados no setor público. Na seqüência, são apresentados alguns dos objetivos da Contabilidade de Gestão no setor público:

a) Permitir a utilização eficiente, eficaz e econômica dos recursos públicos, possibilitando o controle de gestão sobre aspectos concretos da entidade. Antes de abordar este objetivo, é conveniente, como premissa deste estudo, definir o que, de acordo com os conceitos 
estudados, se pode entender por gestão eficiente, eficaz e gestão econômica. A primeira, a gestão eficiente, é aquela que permite transformar os recursos em produtos e serviços de forma mais produtiva e ao menor custo; a segunda, a gestão eficaz, é aquela que permite atingir os objetivos e metas previstos em um programa ou atividade; e a terceira, a gestão econômica, é aquela que estabelece a relação mais favorável entre os recursos empregados e os recursos orçados. Por outro lado, gestão efetiva é aquela que atinge os objetivos internos e externos da entidade. Da mesma forma que nas empresas do setor privado, as entidades públicas têm objetivos internos e externos.

b) Ajudar a determinar o valor apropriado das taxas e preços dos serviços e produtos públicos. $\mathrm{Na}$ medida em que se disponha de informação adequada sobre os custos dos serviços, será possível relacioná-lo, de forma direta, ao correspondente preço ou taxa.

c) Facilitar a elaboração e avaliação dos orçamentos. A fixação clara e precisa dos objetivos e metas é a chave do sucesso no processo de desenhar e orçar os programas e atividades necessárias para atingi-los (sistema de planejamento e orçamento).

d) Apoiar a tomada de decisões referentes à prestação dos serviços ou produção de bens públicos com conhecimento apropriado e detalhado dos custos. Os gestores precisam de informações apropriadas para fazer juízos de valor e assumir decisões responsáveis com o menor risco possível. Essas decisões envolvem o planejamento das atividades, ações corretivas das variações para alcançar os objetivos, ou para atingi-los de forma eficiente, eficaz e econômica, medição dos efeitos ou benefícios (outcomes) causados pela eliminação ou criação de serviços, aplicação de fundos disponíveis, contratação de obras, etc.

e) Facilitar a prestação de contas aos órgãos locais, regionais, nacionais e multilaterais sobre a administração das subvenções recebidas. As informações quanto aos termos de custos constituem uma premissa fundamental para a concessão das subvenções. Os usuários da informação decorrente de um sistema de Contabilidade de Gestão são, além dos gestores da entidade, os responsáveis pelas entidades superiores de controle e os cidadãos.

\section{O CONTROLE DA GESTÃO PÚBLICA: CARACTERIZAÇÃO E OBJETIVOS}

Visto o controle de uma forma simples, pode-se concebê-lo como uma ação preventiva e corretiva contida em cada uma fases do processo administrativo de qualquer organização. Contudo, se são observadas as múltiplas ações que desenvolve o setor público, o controle é apreciado como um processo muito mais complexo. Vásquez ${ }^{4}$, referindo-se ao controle público, afirma que este é um procedimento em que uma pessoa um órgão devidamente autorizado examina ou fiscaliza um ato realizado por outra pessoa ou órgão, com finalidade de verificar se na preparação e cumprimento deste ato têm sido satisfeitos todos os requerimentos exigidos pela lei.

Afasaniev ${ }^{5}$ oferece um conceito mais amplo sobre o controle público ao defini-lo como um sistema de observação e comprovação da correspondência que existe entre o funcionamento de um órgão ou entidade e os instrumentos jurídicos, administrativos e procedimentais adotados. Destaca, o autor, que o referido sistema deve revelar as práticas irregulares contra as normas existentes.

Para outros autores, o controle público refere-se ao acompanhamento, observação, fiscalização e exame da gestão pública, com a finalidade de proteger o patrimônio e promover a maios eficácia, eficiência e efetividade nos serviços prestados, corrigindo as falhas e punindo infratores. Como se pode observar, as definições apresentadas mostram aspectos que vão além do que tradicionalmente tem sido considerado como controle da gestão nos órgãos ou entidades do setor público.

Do ponto de vista técnico, as entidades fiscalizadoras superiores devem desenvolver e aplicar um conjunto de instrumentos e técnicas de diagnóstico, análise de tomada de decisões e dos resultados alcançados, avaliações de desempenho, avaliação do cumprimento dos programas, sistemas de informações e controle administrativo, entre outros. Todas estas atividades

\footnotetext{
${ }^{4}$ in: FERNÁNDEZ, Emilio. Dicionário de derecho público. Argentina: Astrea, 1981.

${ }^{5}$ AFASANIEV, Victor. Direccíon cientifica de la sociedad. Moscú: Progresso, 1978, p. 61.
} 
materializam-se através de inspeções, auditorias financeiras, operacionais e de gestão, revisões administrativas e outras técnicas que, em conjunto, permitem avaliar a gestão cumprida por quem exerce a administração pública.

Referindo-se, especificamente, à Auditoria de Gestão no setor público ou Auditoria Governamental, deve-se reconhecer que tem adquirido cada dia maior relevância pelos efeitos preventivos e corretivos que de correm da sua prática. Neste sentido, cabe destacar o preconizado pelo Instituto Latino-americano de Ciências Fiscalizadoras ILACIF ${ }^{6}$, no que diz respeito à Auditoria Governamental, estreitamente ligada ao controle de gestão pública, já que este constitui a ferramenta indispensável para alcançar os efeitos preventivos e corretivos antes referidos. Segundo o ILACIF, a auditoria governamental não só deve orientar sua ação ao controle financeiro e legal, senão também à avaliação da gestão administrativa da entidade, através da auditoria operacional, com a finalidade de verificar se estão sendo atingidas as metas com eficiência, efetividade e economia.

Deve-se destacar que, segundo o mesmo ILACIF opus citatum, a Auditoria Governamental deve ser entendida em lato sensu, como um complexo metodológico que se divide em vários métodos especializados, com objetivos específicos, mas que apontam todos, de forma convergente, para um mesmo propósito: o exercício completo e "cabal" do controle da gestão pública, mantendo os níveis de qualidade desejados.

As ISA's ou Entidades Fiscalizadoras Superiores tem concordado em que, na atualidade, o objetivo central do Controle Público de Gestão Pública deve estar orientado, basicamente, ao controle da corrupção que envolve as administrações públicas do mundo inteiro; contudo, das definições referenciadas anteriormente podem ser deduzidos os objetivos do controle público, alguns dos quais são apresentados na seqüência:

- Proteger o patrimônio do Estado, controlando, através de auditorias nas entidades públicas, quem maneja fundos públicos;

- Melhorar a eficácia e eficiência na obtenção e administração dos recursos públicos;

- Melhorar os processos, métodos e procedimentos para que os funcionários façam a rendição de contas de forma oportuna e adequada;

- Procurar a máxima utilidade e oportunidade da informação produzida e utilizada no manejo dos recursos alocados;

- Contribuir com o melhoramento da capacidade administrativas dos entes públicos;

- Controlar a execução financeira do orçamento de receitas e despesas;

- Controlar a liquidação e arrecadação das rendas e receitas da Nação.

\section{OS INDICADORES DE GESTÃO NA ADMINISTRAÇÃO PÚBLICA}

Para se adaptar à nova situação de mudanças e evolução do cenário, a administração pública deve executar reformas estruturais que comecem: $1^{\circ}$ ) pela revisão da sua própria dimensão ou tamanho; $2^{\circ}$ ) pela introdução de técnicas de gestão que permitam um funcionamento mais eficaz, eficiente e econômico; $3^{\circ}$ ) pela criação de um sistema de informações úteis para o processo de tomada de decisões.

As reformas estruturais tem apontado para duas direções básicas: $1^{\circ}$ ) A revisão crítica do tamanho do ESTADO, desta forma, os custos de manutenção de estruturas físicas e de despesas de pessoal diminuem também, $2^{\circ}$ ) A introdução de técnicas de gestão que permitam a prestação de serviços de forma mais eficiente e eficaz e, ao mesmo tempo, facilitem a medição do desempenho dos gestores públicos e a prestação de contas à população.

É importante destacar que a utilização de indicadores de gestão, como técnicas para a avaliação da gestão, como, não garante a resolução de todos os problemas relacionados à má prestação de contas e à accountability ou Responsabilidade da administração pública; apenas ajuda a desenvolver um sistema integrado de informação baseado nestes indicadores que, junto a outros instrumentos, possibilitam dar uma resposta às demandas da sociedade relativas aos

\footnotetext{
${ }^{6}$ ILACIF - Políticas operativas y técnicas. Ecuador: Quito, 1977.
} 
gestores públicos. Desta forma, o gestor público poderá contar com um sistema complexo de informações o qual the permite selecionar as decisões mais adequadas e conhecer 0 tipo de serviço que administra o gestor público, as atividades necessárias para produzi-lo e os custos associados, com a finalidade de identificar e controlar os recursos gerenciados de maneira a atingir os objetivos da organização de forma eficiente e eficaz.

A aplicação de indicadores de gestão persegue um propósito que pode ser enfocado de duas formas diferentes. A primeira, da perspectiva do gestor público ao proporcionar ferramentas que the permitam gerenciar melhor os recursos disponíveis, ao mesmo tempo em que possa prestar contas ou informar a comunidade sobre o uso destes recursos; a segunda, da ótica do cidadão e de entidades fiscalizadoras superiores, que poderão exercer um melhor controle e avaliação do desempenho do gestor público.

A mesma associação identifica algumas vantagens ao avaliar a gestão pública, quando são utilizadas das técnicas de gestão como, por exemplo, os indicadores de gestão. As vantagens superam, de modo extraordinário, as limitações antes descritas. Algumas dessas vantagens estão em que permitam: conhecem os objetivos e as metas que a organização persegue obter informação em detalhe das atividades e os custos envolvidos para atingir os objetivos; conhecer os resultados e compará-los com padrões estabelecidos facilitando o entendimento dos termos eficácia, eficiência e economia; melhorar o processo de prestação de contas e controlar mais efetivamente os recursos, entre outras vantagens não menos importantes.

\section{UTILIZAÇÃO INDICADORES}

O controle da gestão é parte do processo administrativo. É responsabilidade da Administração da entidade, especificamente da Diretoria do Organismo, estabelecer os indicadores com os quais será medida e avaliada a sua própria gestão. Cabe aos órgãos superiores de fiscalização e controle auditar e avaliar: a) se foram estabelecidos os indicadores; b) se estes indicadores são os mais apropriados para medir e avaliar a gestão; c) se estão sendo providenciados os corretivos necessários.

O conhecimento e familiaridade, por parte do auditor, dos indicadores e índices e do que procuram medir, além de como correlacioná-los, é básico. Por exemplo, existem indicadores para medir a produtividade que relacionam critérios de qualidade, eficiência, efetividade; se isto não está claro para o auditor de gestão, dificilmente atingirá os objetivos da auditoria.

Os indicadores não constituem um objetivo, mas uma ferramenta ou meio de avaliação através da sua comparação com padrões preestabelecidos. Segundo Price Waterhouse (Espiñeira Sheldon \& Associados, Contadores Públicos) ${ }^{7}$, os indicadores podem ser definidos como:

\section{"Unidades de medição que permitem acompanhar e avaliar em forma periódica, as variáveis consideradas importantes em uma organização. Esta variação é feita através da comparação com os valores ou padrões correspondentes preestabelecidos como referência, sejam internos ou externos à organização."}

Para utilizar os indicadores de forma correta, é necessário responder a algumas perguntas como: O que será medido? Qual é a informação necessária? Quais são os valores de comparação ou referência (padrões)? Como será obtida a informação?, entre outras. Para responder a estas perguntas é necessário conhecer as condições ou características qualitativa dos indicadores.

Os indicadores devem ser capazes de medir as atividades realizadas, os resultados obtidos e os recursos utilizados e a sua comparação com os valores-padrão preestabelecidos deve permitir identificar variações importantes. A validade de um indicador e sua força, para avaliar uma gestão, depende de suas qualidades. As principais qualidades de um indicador são:

\footnotetext{
${ }^{7}$ PRICE WATERHOUSE. Como lejorar la rendicíon de cientas em los entes gubernamentais. Caracas: PW, 1984 , p. 75.
} 
- Relevância: os valores fornecidos devem ser imprescindíveis para controlar, avaliar, tomar decisões, prestar contas, estabelecer corretivos;

- Pertinência: adequação do indicador para o que se quer medir e sua validade no tempo e espaço;

- Objetividade: o cálculo deve considerar as magnitudes do valor. Não há possibilidades de interpretações erradas;

- Sensibilidade: a unidade de medição do indicador deve ser eficaz, para permitir identificar pequenas variações, se estas são de importância;

- Precisão: a margem de erro deve ser calculada e aceitável, ou seja, que não distorça sua interpretação;

- Custo-benefício: o custo para obter o resultado da aplicação do indicador deve ser menor que o benefício da informação que fornece e, ao mesmo tempo, deve ser fácil de calcular e de interpretar.

\section{TIPOS E CLASSIFICAÇÃO DE INDICADORES}

Os indicadores podem ser classificados de diversas formas; contudo a mais comum identifica três critérios: de acordo com a NATUREZA; de acordo com o OBJETO; de acordo com a ÂMBITO (Figura1). De acordo com a sua natureza, os indicadores são agrupados segundo o critério ou atributo que se procura avaliar ou medir, ou seja, eficiência, eficácia, economia, efetividade, eqüidade, excelência, cenário, perpetuidade e legalidade.

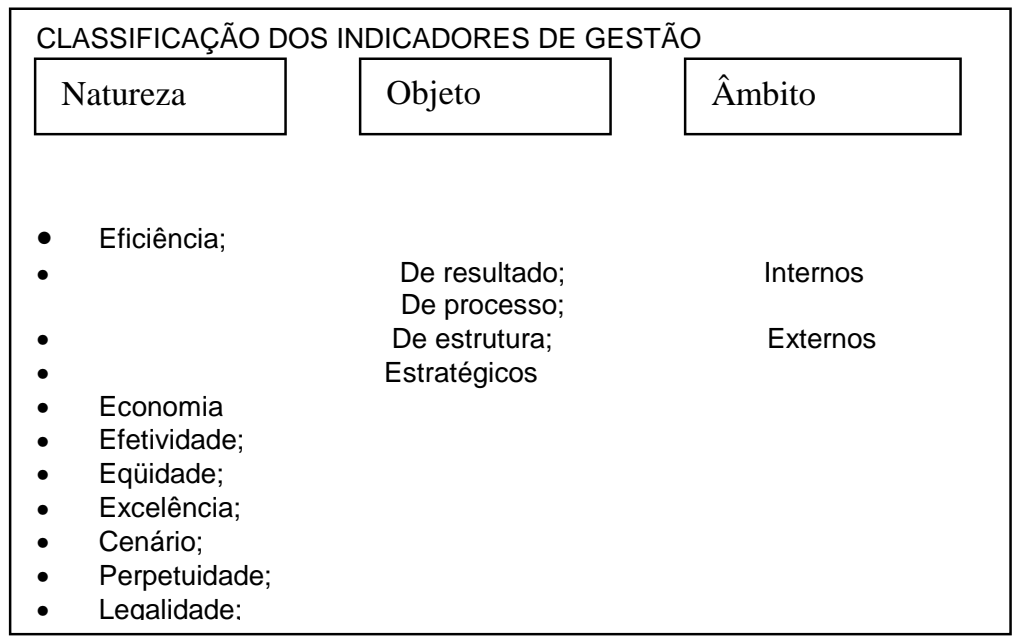

De acordo com o objeto, os indicadores são agrupados segundo a alvo de medição ou avaliação. Desta forma são classificados em : a) Indicadores de resultado: resultados obtidos vs, resultados esperados ou desejados. Normalmente referem-se a indicadores de eficácia considerando a consecução dos objetivos fixados; b) Indicadores de Processo: referem-se aos indicadores de eficiência e são utilizados normalmente quando não é possível utilizar indicadores de resultado; c) Indicadores de Estrutura: procuram avaliar o custo e a utilização dos recursos. Pela sua natureza, estes indicadores podem ser considerados como indicadores de economia; d) Indicadores Estratégicos: procuram avaliar os aspectos não relacionados diretamente com as atividades desenvolvidas, mas que tem efeito sobre os resultados destas atividades. Normalmente estes fatores são de caráter externo.

De acordo com a âmbito de atuação, os indicadores são a) internos: consideram variáveis de funcionamento interno ou da entidade ou organização; e b) externos: consideram o efeito ou impacto, fora da entidade, das atividades e serviços prestados. 


\section{CRITÉRIOS PARA DESENHAR OS INDICADORES DE AVALIAÇÃO DA GESTÃO PÚBLICA}

Partindo da premissa de que a auditoria de gestão objetiva determinar a eficácia, eficiência e economia de qualquer parte de uma organização, ou da organização em conjunto, pode-se inferir que os atributos mais importantes para determinar ou desenhar os indicadores de gestão sejam precisamente eficácia, eficiência e economia.

Muita controvérsia existe em torno da utilização desses atributos como base para estabelecer padrões de comparação, de medição e de avaliação do desempenho de um gestor, especialmente se este gestor pertence ao setor público. Por esta razão, é fundamental definir e confrontar estes conceitos para atingir um melhor entendimento dos tópicos que se apresentam na seqüência.

A efetividade (comparação dos resultados alcançados vs. O ideal), muitas vezes é utilizado como sinônimo de eficácia. Esta última refere-se ao grau de consecução dos objetivos programados, ao passo que a eficiência refere-se à quantidade, tipo, custo $r$ qualidade dos recursos utilizados para atingir esses objetivos e a economia, por sua vez, concerne à consideração do custo dos recursos utilizados no processo, confrontando o que se paga por estes recursos com o que se deve pagar.

Por enquanto pode-se notar que o fator comum entre estes três conceitos é o atingimento dos objetivos programados. Para ilustrar esta comparação pode-se apresentar o seguinte exemplo: a eficácia pode-se entender como a capacidade de uma fábrica de produzir peças sem defeito:, quer dizer, quanto mais peças sem defeito são produzidas em relação ao total de peças fabricadas ,a empresa é mais eficaz. Por outro lado, a eficiência procura estabelecer a relação mais apropriada entre o número de peças produzidas e a quantidade, tipo e qualidade dos recursos utilizados. Nesta relação, não se pode esquecer dos custos dos recursos utilizados no processo que representa o terceiro (sem conotações de grau de importância) critério envolvido; ou seja, a economia diz respeito ao menor valor possível do produto mantendo a qualidade.

Uma dificuldade da auditoria de gestão é a seleção e desenho dos critérios específicos que servirão para medir e avaliar os atributos de eficiência, eficácia e economia. Em auditoria financeira, cujo objetivo é determinar a razoável apresentação dos relatórios contábeis, os critérios amplos utilizados para esta medição estão conformados pelos Princípios Fundamentais de Contabilidade e os critérios específicos são detalhados nos objetivos de auditoria determinados no planejamento.

$\mathrm{Na}$ seqüência, são apresentados, em detalhes os atributos normalmente utilizados para medir e avaliar a gestão dos funcionários da administração pública. É importante ressaltar que existe uma grande dificuldade ao se tentar avaliar estes atributos isoladamente, pois esse aspecto pode contribuir para as diferenças em conceitos dos diversos autores e pesquisadores. Os atributos em questão são os seguintes:

Eficiência: este é o primeiro da trinca de elementos chave na avaliação da performance (eficiência, eficácia e economia ou também chamados os Três E's.). A eficiência pode-se expressar quanto à relação existente entre os bens e serviços consumidos (entradas ou inputs do processo) e os bens e serviços produzidos (saídas ou outputs do processo).

Assim, uma performance eficiente é a maximização dos resultados com recursos determinados ou a obtenção ou prestação de um bem ou serviço com o mínimo possível de recursos, mantendo a qualidade e quantidade desejada. Aplicando-se o raciocínio contrário, existe ineficiência sempre que:

1) o resultado de uma atividade ou trabalho não tem utilidade alguma;

2) produz-se excesso ou déficit de produtos ou serviços;

3) incrementa-se a quantidade e qualidade dos materiais e não é obtida a melhoria desejada na qualidade e quantidade do produto ou serviço;

4) mantendo os mesmos recursos, em termos relativos, diminui a quantidade ou qualidade dos produtos e serviços. 
Eficácia: a eficácia de uma entidade ou gestor público é medida pelo grau de comprimento dos objetivos e metas fixados nos programas de ação. Esta medida é feita através da comparação entre os resultados realmente obtidos e os resultados esperados ou previstos nos planos ou programas de ação, independentemente da quantidade, qualidade e custo dos recursos envolvidos em atingir estes objetivos.

Desta forma, para poder avaliar a eficácia é necessária a existência de um planejamento por programas em que as metas e objetivos estejam claramente identificados e, na medida do possível, quantificados, descrevendo-se as atividades necessárias para atingi-los. A avaliação da eficácia estabelece a relação não só entre os resultados obtidos e os planejados, previstos ou esperados, senão também com o resultado ótimo. É importante destacar que a otimização do resultado deve ser a consecução do resultado planejado; em outras palavras, qualquer variação ou divergência quanto ao plano pode-se considerar, de uma forma ou outra, como uma eficácia.

Economia: este elemento, segundo muitos autores da área administrativa, fecha o conjunto de três critérios básicos (os três E's), para a avaliação da performance dos gestores públicos e privados. Este critério de avaliação de avaliação da gestão refere-se às condições de aquisição dos diferentes recursos (financeiros, humanos, materiais, etc) pela entidade em questão. A consideração deste atributo supõe o conhecimento dos recursos e a sua comparação com padrões preestabelecidos. Desta ótica, uma operação considera-se econômica quando se dão, em forma concomitante, os fatores a) tempo adequado, b) menor custo, c) quantidade adequada, d) qualidade esperada; ou seja, a aquisição realizou-se em tempo adequado, com o menor custo possível, na quantidade adequada e com a qualidade preestabelecida. Pode-se dizer que a economia é atingida quando são adquiridos recursos adequados (em quantidade e qualidade) ao menor custo possível, considerando as condições de aquisição.

Neste ponto, após serem abordados os três critérios considerados fundamentais para o estudo e avaliação da performance na gestão pública, é oportuno fazer um relacionamento entre estes critérios, com a finalidade de compreender melhor seu significado e utilização, evitando-se possíveis erros de interpretação. Pode-se observar que a eficácia está claramente diferenciada da economia e da eficiência; entretanto a diferenciação entre os dois últimos (eficiência e economia) já não é tão clara. Esta afirmação fica demonstrada pelo fato de que alguns países como Austrália, Alemanha, França e Itália consideram a economia como uma parte da eficiência.

Para isto, é preciso destacar que a eficiência relaciona as entradas e saídas reais; a economia relaciona entradas reais vs. entradas previstas; a eficácia relaciona saídas reais vs. saídas previstas, conforme se visualiza na Figura 2:

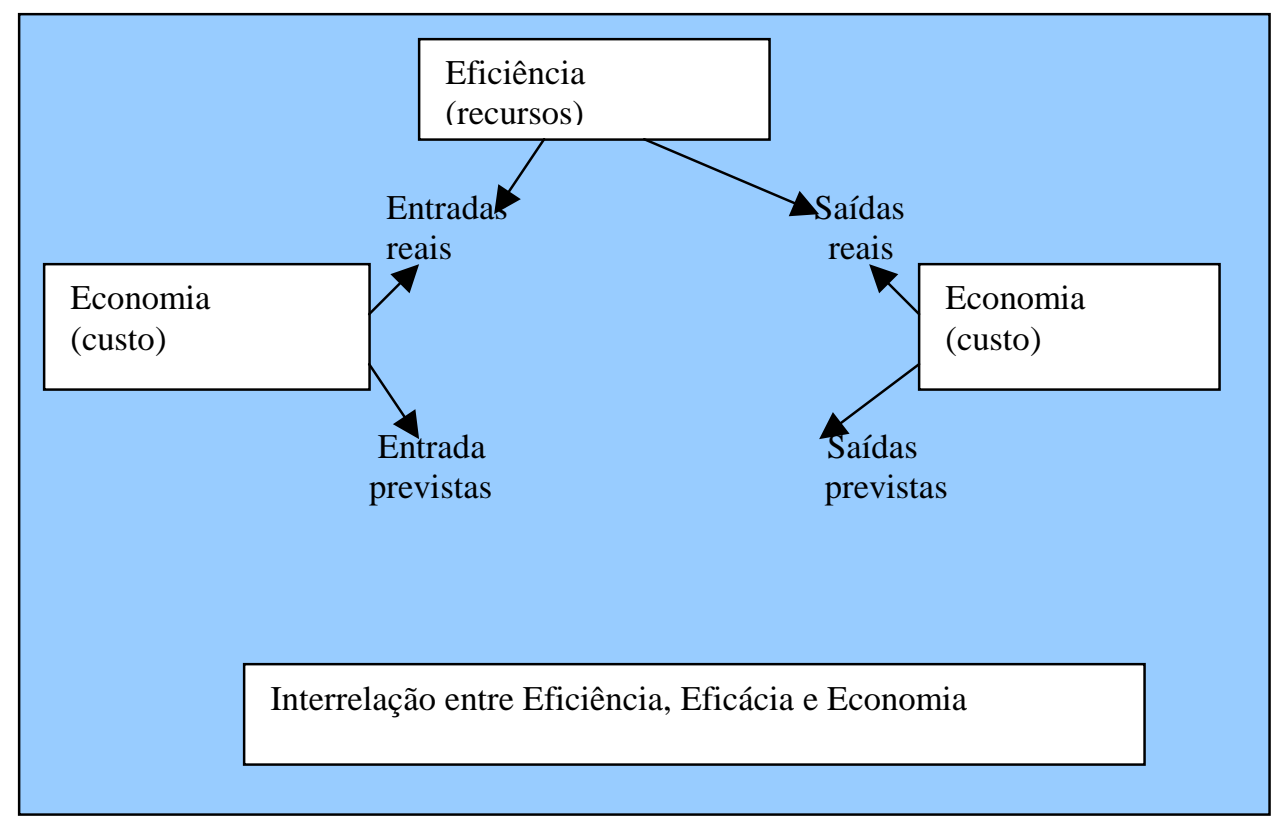

Caderno de Estudos, São Paulo, FIPECAFI, no21 - Maio a Agosto/1999 
Figura 2

Entre estes três conceitos ou critérios deve existir um equilíbrio. Se, por exemplo, é possível ser eficaz atingindo os objetivos por meio da utilização de recursos de forma limitada e irracional, isto permite induzir que é possível ser eficaz sem ser eficiente. Por outro lado, se para ser econômico e eficiente, os recursos não são utilizados de forma racional e adequada, os objetivos podem não ser atingidos como o esperado, levando a incorrer em ineficácia.

\section{EFETIVIDADE}

Este atributo procura medir o impacto ou efeito que tem atuação pública, como a prestação de um serviço sobre a população alvo. Os indicadores desenhados sob este atributo chamam-se também indicadores de impacto ou efetividade. Isto, em virtude, basicamente, de que na administração pública não se pode medir com base nas saídas ou produtos somente; devem ser considerados os produtos em relação aos resultados e o impacto que geram sobre a comunidade.

\section{EQÜIDADE OU} IGUALDADE

Este atributo, considerado nos serviços que presta a administração pública; pode-se entender como fundamental numa gestão. Com este critério procura-se medir a igualdade de possibilidades que têm os grupos sociais menos favorecidos, como regiões pobres, favelas, pessoas incapacitadas, idosos, indigentes, etc., comparando-as com as possibilidades da média do país ou região. Tenta fornecer informação útil ao gestor, permitindo-lhe garantir a igualdade de acesso aos recursos a quem tem direito a eles, medindo a distribuição eqüitativa dos serviços públicos entre a população.

\section{EXCELÊNCIA}

Este atributo mede a qualidade dos serviços públicos. O enfoque deste é dirigido para o beneficiário do serviço ou "cliente". O desenho de indicadores de qualidade é uma necessidade para as administrações públicas, porque, considerando o cenário atual no qual existem maior exigência do cidadão e menor quantidade de recursos, os gestores públicos devem aplicar modelos de gestão empresarial, satisfazendo às necessidades razoáveis dos "clientes" com o mínimo consumo de recursos. A aplicação de indicadores de qualidade significa uma transição cultural que proteja as organizações públicas para o beneficiário do serviço, introduzindo medidas que permitam orientá-las para o Kaizen ou melhoria contínua. É importante destacar que os indicadores de qualidade estão orientados a medir a qualidade e não a controlá-la. 
O processo de globalização e de mudanças constantes que existe atualmente exige o conhecimento do cenário e a capacidade de adaptação de forma flexível e rápida às mudanças que nele se produzem. O acesso à informação sobre a evolução sócio-econômica do cenário, assim como o conhecimento das ações de serviços e produtos desenvolvidos pelos elementos que interatuam neste contexto, são fundamentais para a administração pública, de forma antecipada e não como uma reação, se adapte às necessidades dos cidadãos que serve.

\section{PERPETUIDADE} OU PERENIDADE

Refere-se à capacidade da administração pública de manter um serviço com a qualidade esperada durante um longo período. Não é suficiente atingir eficientemente os objetivos de um programa, senão manter os benefícios que produzem estes objetivos sobre as mudanças adversas do cenário. Desta forma, procura-se garantir um serviço não só eficiente, eficaz, eqüitativo, excelente, econômico, como também contínuo e duradouro.

\section{LEGALIDADE}

Este é um dos mais aplicáveis à administração pública, em virtude do grande número de normas, leis e regulamentos a que estão submetidas as entidades do setor público. Por muito tempo, as auditorias praticadas em organizações do setor público limitavam-se à verificação do cumprimento legal e normativo aplicável, reduzindo-se de forma considerável os benefícios de um auditoria de gestão na forma como é praticada hoje. Este marco normativo não deve ser violentado sob o pretexto de atingir uma maior eficácia, eficiência e economia, ou nenhum outro critério (abordado ou não com antecedência), conformando assim a existência de um marco ético e moral da cultura de controle da gestão pública. Os indicadores desenhados sobre o critério da legalidade procuram facilitar a prestação de contas dos gestores públicos facilitar a prestação de contas dos gestores públicos e são considerados básicos na avaliação da gestão por parte dos órgãos superiores de controle público.

\section{MENSURAÇÃO DA GESTÃO DE UM ORGANISMO PÚBLICO}

A variação fundamental para o setor público é avaliar a gestão através da análise e confrontação restrita dos valores monetários da contabilidade tradicional (custos, receitas, despesas), ou introduzir, na análise e avaliação, outras variáveis não monetárias que permitam relacionar as variáveis tradicionais à finalidade da entidade pública.

As entidades privadas são tradicionalmente diferenciadas das públicas pelo contexto em que se entende o objetivo que persegue cada uma. As primeiras procuram obter o maior lucro possível como retorno dos investimentos para atender às necessidades internas da organização, ou seja, oferecer retribuição aos proprietários através dos dividendos. As entidades públicas procuram atender às necessidades da população (proprietários), no que tange à qualidade e quantidade, para retribuir os impostos que arrecadam. 
Como premissa para este estudo, deve-se entender que a diferença principal entre as entidades públicas e privadas é a forma como são distribuídos os resultados ou "lucros" e não o objetivo. O objetivo para ambas é o mesmo "obter maior lucro para o retorno dos investidores", atendendo às necessidades internas e externas da entidade, porém as palavras "lucro" e "investidores" devem, ser consideradas com diferentes conotações para cada caso (público e privado). Segundo Hélio J. Teixeira ${ }^{8}$ :

"a administração pública e suas entidades, em certo sentido, pertencem aos cidadãos. No entanto, não há, entre nós, em geral, canais adequados para que os cidadãos façam ouvir suas reivindicações, nem há meios efetivos de informação sobre o que se passa dentro da administração pública. Daí agravar-se a larga margem de insatisfação popular para com os serviços prestados pelo Estado e a desconfiança do público em geral sobre a forma como são geridos os recursos, pagos direta ou indiretamente pela população."

A afirmação anterior permite inferir que os cidadãos são os investidores que existem no setor privado. Isto requer que a gestão se atualize no que se concerne a eficiência, eficácia e economia para poder retribuir os investimentos feitos através dos impostos arrecadados. De acordo com esta afirmação, o setor público deve desenvolver a sua atividade em concordância com a filosofia do máximo aproveitamento dos recursos, procurando atingir o objetivo de lucro, por meio de uma gestão eficiente, econômica e eficaz, ou seja, otimizar os recursos e maximizar os resultados.

Existem também entidades do setor público que prestam serviços e geram recursos próprios. Nesse caso, a confrontação de custos/despesas e receitas é de grande utilidade para conhecer a capacidade de financiar suas próprias atividades. O resultado, nesta perspectiva, é a capacidade de recuperar os custos incorridos na prestação do serviço.

Para medição e avaliação da gestão pública, cuja finalidade é realizar atividades orientadas à satisfação das necessidades da sociedade sem que exista a retribuição por parte dos usuários, os instrumentos de medição devem estar relacionados com os objetivos que justificam a existência e permanência da entidade. Para isso, o sistema de informação deve fornecer dados que permitam obter indicadores de eficiência (custos vs. atingidos) e economia (custos dos recursos utilizados vs. os custos orçados); ou seja, dados que relacionem os custos incorridos com : a) os objetivos programados ou esperados; b) os objetivos atingidos; c) o efeito nos usuários e comunidade.

\section{LIMITAÇÕES AO CONTROLE DE GESTÃO GOVERNAMENTAL ATRAVÉS DE INDICADORES DE GESTÃO}

Segundo a Associación Española de Contabilidad y Administracíon de Empresas, a utilização e a aplicação de técnicas de gestão, como por exemplo, os indicadores para medir e comparar o desempenho dos gestores no setor público, são muito mais complicados, se comparadas com o setor privado. Algumas das limitações mais conhecidas são a falta de indicadores, a dificuldade para fixar e quantificar os objetivos sociais, a utilização de termos não monetários, a falta de clareza nos objetivos, metas e atividades realizadas, entre outros não menos importantes.

A implantação e a utilização de qualquer sistema de controle para a medição da gestão causam diversos tipos de problemas entre os funcionários da entidade, gerando todo tipo de resistência; ainda mais quando na medição da gestão é minimizada a subjetividade através do uso de indicadores. A chave do sucesso para a implantação, normalmente, está em abordar o problema com uma estratégia de informação e participação geral persuadindo aos funcionários quanto ao espírito crítico deste instrumento, permitindo o melhoramento contínuo (kaizen) da

\footnotetext{
${ }^{8}$ TEIXEIRA, Hélio et..al. Remodelando a gestão pública. São Paulo: Blücler, 1994, p. 10-11.
} 
gestão. As resistências são maiores quando os sistemas de controle incrementa a transparência da gestão, dificultando manejos inadequados dos recursos administrados, entre outras.

Quiça o problema principal na implementação de sistemas de controle de gestão na administração pública seja a dificuldade na mensuração do custo das entradas (inputs), da qualidade das saídas ou serviços (outputs) e dos efeitos ou benefícios advindos (outcomes). A dificuldade de mensurar, primeiramente, os objetivos sociais de um programa ou atividade pública e, em segundo lugar, os efeitos favoráveis ou desfavoráveis derivados de outro programa ou atividade representa outra importante limitação à utilização de sistemas de Controle de Gestão através de indicadores.

De qualquer forma, os benefícios da utilização de indicadores para avaliar a gestão pública superam as limitações apresentadas. Apesar das dificuldades, os produtos ou outputs devem ser medidos e confrontados: a) com outros de similares características; b) com eles mesmo no transcorrer do tempo; c) com os outputs esperados; d) com outputs preestabelecidos como padrões de referência. Ë preciso, também, confrontar estes outputs com o custo, qualidade, benefício, inputs utilizados, etc., relacionados ao serviço. Esta informação servirá de banco de dados no desenho dos indicadores adequados para avaliar a gestão em qualquer perspectiva (eficiência, eficácia, economia, etc.).

\section{CONCLUSÕES}

Pode-se enfatizar que a Auditoria de Gestão, em essência, tem se constituído como uma concepção necessária para o fortalecimento das organizações públicas no seu processo de ajustes às modernas práticas de gestão. Esta doutrina, longe de incentivar esquemas mecânicos clássicos da administração, procura gerar mudanças na forma de pensar e no sistema de mensuração dos serviços públicos, com o objetivo de se considerarem as organizações públicas como redes associadas orientadas a alcançar o bem comum.

As profundas limitações dos sistemas tradicionais de contabilidade utilizados no setor público para avaliar a gestão tem sido a motivação principal da procura de sistemas modernos de informação, que considerem medições não só monetárias, mas que permitam, também a avaliação da qualidade da gestão pública no que diz respeito a eficiência, eficácia e economia.

A consolidação de uma Auditoria de Gestão, seja através de indicadores de gestão ou de outra técnica, não só constitui um aporte importante na modernização da Administração Pública e do Estado; mas também representa a materialização de uma exigência técnica derivada da própria globalização para ajudar aos gestores públicos a atingir os objetivos de modo econômico, eficiente, eficaz e transparente. Destaca-se ao mesmo tempo, a importante contribuição da Auditoria de Gestão na modernização das gestões públicas; estes últimos, como verdadeiros agentes de mudanças para uma nova cultura organizacional.

A existência e consideração de indicadores de gestão não pretende suprir as deficiências da contabilidade pública, contudo representa um instrumento interessante para seu desenvolvimento. No futuro, será possível a decisão de utilizar sistemas de informação em redes INTERNET, internas (INTRANET) e externas (EXTRANET) para a apresentação de indicadores financeiros que possibilitem a avaliação por gestores e qualquer outro interessado, contribuindo ao desenvolvimento da cultura de controle público, não existente nos países do terceiro mundo.

A Auditoria de Gestão é uma nova e recente forma de fiscalização da utilização dos fundos públicos, em contínua evolução e desenvolvimento. Assim, não está livre de dificuldades e não é infalível, mas oferece um considerável potencial para agregar valor e construir um melhor serviço público, como tem sido demonstrado pelas instituições Superiores de Auditoria dos países de língua inglesa. Esta experiência facilita, sem dúvida, a aprendizagem e globalização das técnicas e metodologias de auditoria governamental, o que tornará este instrumento mais efetivo. O Controle de Gestão e a Auditoria de Gestão são atividades técnicas e metodologias de auditoria governamental, o que tornará este instrumento mais efetivo. O Controle de GESTÃO E A Auditoria 
de Gestão são atividades técnicas e profissionais que não devem ser consideradas de forma isolada, como funções atribuídas a organismos de controle, em um esquema institucionalista e burocrático, senão como parte do processo: planejamento-execução-controle, o que é inerente à atividade administrativa, qualquer que seja a índole ou natureza jurídica da entidade.

A tentativa de estabelecer o Controle e Auditoria de Gestão constitui um avanço positivo na tarefa de atualização da administração pública mundial e, em especial, da latino-americana. Não seria objetivo acreditar que isso é uma realidade pelo grau de desenvolvimento que apresenta esta corrente nos países de língua inglesa, através das Entidades Fiscalizadoras Superiores. A realidade deste lado do mundo é diferente e acredita-se estar em fase experimental.

Uma das técnicas adequadas para se atingir um controle de gestão apropriado é a utilização de parâmetros de medida que possam ser comparados com outros preestabelecidos para avaliar a performance dos gestores públicos. A utilização dos indicadores de gestão tem sido peça fundamental no desenvolvimento e fortalecimento : a) da administração pública; b) da qualidade dos serviços que presta; c) do grau de satisfação das necessidades dos cidadãos nos países de língua inglesa.

O fortalecimento das instituições democráticas é uma grande missão, especialmente nos países em desenvolvimento. A administração pública e a avaliação da gestão de seus gestores são a base principal dessas instituições. Que melhor forma de apoiar a democracia senão garantindo a credibilidade dos cidadãos em seu Governo, a confiança e fé na administração de recursos públicos. É esta a principal função social do auditor da gestão pública, além de promover a honestidade na gestão dos recursos do povo.

\section{RESUMO}

Os governos contemporâneos, através das entidades públicas enfrentam, na atualidade, grandes desafios. Momentos em que a crise mundial econômica, política e social se traduzem na perda de legitimidade e credibilidade do povo, em seus gestores públicos, surge a imperiosa necessidade de executar mudanças estruturais na forma tradicional de administrar os recursos públicos e de prestar contas.

Hoje, inspirado pela crescente corrupção que atinge os países do mundo inteiro, importantes avanços tem sido alcançados em matérias de gestão pública e seu controle. Efetivas técnicas gerenciais tem sido desenvolvidas, principalmente pelos países de língua inglesa, através das Instituições Superiores de Auditoria, para medir, avaliar e controlar a performance do gestor público.

Sistemas tradicionais de contabilidade, utilizados para medir e avaliar a gestão pública, não dão suporte necessário para atingir uma eficiente, econômica e eficaz administração dos recursos públicos nem auxiliam aos gestores no processo de tomada de decisões que permita, à entidade, dar respostas rápidas oportunas e adequadas frente a um cenário em constantes mudanças.

O controle de gestão baseado na avaliação da legalidade das ações dos gestores públicos e, em medições tradicionais exclusivamente sobre aspectos quantitativos (monetários e financeiros) da gestão, não é suficiente para suportar, adequadamente, o processo de tomada de decisões. Aspectos qualitativos da gestão devem ser considerados, junto aos primeiros, na avaliação da performance pública através dos indicadores de gestão.

Critérios de eficiência, eficácia e economia foram, até pouco tempo, quase exclusivos das empresas do setor privado na medição dos resultados alcançados. Nas instituições públicas, onde o ânimo de lucro é entendido como a satisfação das necessidades da sociedade e os recursos administrados são cada vez mais limitados frente à crescente população; resulta obrigatório a gestão sob estes critérios com a finalidade de otimizar e maximizar os recursos utilizados na prestação de serviços e produção de bens de uso público. 


\section{REFERÊNCIAS BIBLIOGRÁFICAS}

ARISTIGUETA, Alberto Silva. La gestíon pública. in: Seminário Nacional de Auditoria de Estado. Venezuela, 1997.

AFASANEV, Victor. Direccíon Cientifica de la sociedad. Moscú: Progresso, 1978.

FERNÁNDEZ, Emilio. Diccionário de derecho público. Argentina: Astrea, 1981.

GUERREIRO, Reinaldo. A meta da empresa: seu alcance sem mistérios. São Paulo: Atlas, 1996.

GUZMÁN, Miguel D. A auditoria compreensiva: um moderno concepto em la auditoria, México: 1991.

ILACIF. Políticas operativas y Técnicas. Ecuador: Quito, 1977.

PRICE WATERHOUSE - Como lejorar la rendicíon de cientas em los entes gubernamentales. Caracas: PW, 1984.

TEIXEIRA, Hélio et. Al. Remodelando a gestão pública. São Paulo: Edgard Blücher Ltda, 1994. 